\title{
Engineering Nanomaterials to Address Cell-Mediated Inflammation in Atherosclerosis
}

\author{
Sean Allen ${ }^{1} \cdot$ Yu-Gang Liu ${ }^{1} \cdot$ Evan Scott $^{1}$ (D)
}

Received: 20 December 2015 / Accepted: 20 February 2016/Published online: 3 March 2016

(C) The Regenerative Engineering Society 2016

\begin{abstract}
Atherosclerosis is an inflammatory disorder with a pathophysiology driven by both innate and adaptive immunity and a primary cause of cardiovascular disease (CVD) worldwide. Vascular inflammation and accumulation of foam cells and their products induce maturation of atheromas, or plaques, which can rupture by metalloprotease action, leading to ischemic stroke or myocardial infarction. Diverse immune cell populations participate in all stages of plaque maturation, many of which directly influence plaque stability and rupture via inflammatory mechanisms. Current clinical treatments for atherosclerosis focus on lowering serum levels of low-density lipoprotein (LDL) using therapeutics such as statins, administration of antithrombotic drugs, and surgical intervention. Strategies that address cell-mediated inflammation in atherosclerosis are lacking and consequently have recently become an area of considerable research focus. Nanomaterials have emerged as highly advantageous tools for these studies, as they can be engineered to target specific inflammatory cell populations, deliver therapeutics of wide-ranging solubilities and enhance analytical methods that include imaging and proteomics. Furthermore, the highly phagocytic nature of antigen-presenting cells (APCs), a diverse cell population central to the initiation of immune responses and inflammation, make them particularly amenable to targeting and modulation by nanoscale particulates. Nanomaterials have therefore become essential components of vaccine formulations and treatments for inflammation-driven pathologies like
\end{abstract}

Evan Scott

evan.scott@northwestern.edu

1 Department of Biomedical Engineering, Northwestern University, Evanston, IL, USA autoimmunity, and present novel opportunities for immunotherapeutic treatments of CVD. Here, we review recent progress in the design and use of nanomaterials for therapeutic assessment and treatment of atherosclerosis. We will focus on promising new approaches that utilize nanomaterials for cell-specific imaging, gene therapy, and immunomodulation.

\section{Lay Summary}

CVD continues to be the leading cause of death in the developed world and is a considerable economic burden. The underlying mechanism of most CVD is atherosclerosis, an inflammatory condition characterized by cellularly complex plaque deposits within arterial vessel walls. Therapies that adequately address cell-mediated inflammation and diagnostic tools for early detection of vulnerable plaques are critical weaknesses of current clinical strategies for treating CVD, and nanomaterials have been engineered to uniquely address both of these needs. Here, we review recent progress in the use of nanomaterials designed to enhance imaging and therapeutic intervention of atherosclerotic inflammation.

Keywords Nanomaterial · Atherosclerosis · Imaging · Diagnostic $\cdot$ Gene therapy $\cdot$ Immunotherapy

\section{Introduction}

Atherosclerosis is an immunologically complex inflammatory condition within the intima of arterial vessels and a primary cause of cardiovascular disease (CVD). CVD continues to be the leading cause of death in the developed world and is responsible for over $17 \%$ of national health care expenditures alone in the United States. With $40 \%$ of the US population projected to experience some form of CVD by 2030, the total direct medical costs are expected to reach $\$ 818$ billion [1]. 
Numerous studies have implicated low-density lipoprotein (LDL) as the instigator of atherogenesis, and a lowering of lifelong LDL levels by only $30 \%$ via diet $[2,3]$ or mutation $[4,5]$ can reduce the risk of an adverse cardiovascular event by $90 \%$. In comparison, a similar $30 \%$ decrease in LDL levels by drugs such as statins, which have become a staple for therapeutic treatment of CVD [6], only reduce the risk of an event by $30 \%$. The human body has long been estimated to only require LDL cholesterol levels of approximately $25 \mathrm{mg} /$ dl [7], while the mean value resulting from the high-fat diets prevalent in North America and Europe is $136.2 \mathrm{mg} / \mathrm{dl}$ [8]. As a result, almost everyone over the age of twenty has subclinical atherosclerotic lesions [9]. Therapies must therefore account for the plaques that a lifetime of a Western diet has generated in the vessel walls of patients by addressing additional contributing factors, such as cell-mediated inflammation [10]. Atherosclerosis is primarily treated through surgery and/or a combination of therapeutic drugs such as platelet inhibitors, statins, antihypertensives, and thrombolytics. Surgical intervention can involve stenting or artery bypass surgery. These current clinical strategies inadequately address the inflammatory component of atherosclerosis [11], and the targeting and modulation of inflammatory immune cells and their expressed factors may present a viable component of effective treatment regimens [12].

The activation state and function of inflammatory cells are strongly influenced by interactions with and factors released by a phagocytic cell population known as antigen-presenting cells (APCs), which consists of diverse subsets of monocytes, macrophages, B cells, dendritic cells (DCs), and epithelial cells [13]. A primary role of these cells is to serve as sentinels that collect and process foreign and pathogenic molecules and particulates to generate appropriate immune responses, often stimulating controlled inflammation. Due to the highly phagocytic nature of APCs, they can be readily targeted by rationally designed nanoscale materials via multiple mechanisms. For example, the vast majority of intravenously injected nanomaterials are eventually cleared systemically by macrophages in the spleen and liver regardless of their intended in vivo targets, which was originally called the reticuloendothelial system and now referred to as the mononuclear phagocyte system (MPS) [14-16]. Nanomaterials have thus emerged as key components of delivery systems engineered to influence inflammation and immune responses, most notably vaccines and immunotherapies [17, 18]. Consequently, nanomaterials have found recent utility for targeting and modulating inflammatory cells that contribute to atherosclerosis. Encapsulation within nanomaterials can increase the pharmacokinetics of therapeutic drugs, improving their targeting to the lesions, and may reduce the need for surgery. Association with fluorophores, contrast agents and targeting ligands allow nanomaterials to serve as sensitive imaging tools to improve diagnosis of CVD and the efficacy of intervention.
Furthermore, LDL is itself a nanoparticle composed of up to 1,500 cholesterol esters and a single apolipoprotein B molecule, which maintains a diameter of $21.4 \pm 1.3 \mathrm{~nm}$ diameter and a height of $12.1 \pm 1.1 \mathrm{~nm}$ with strikingly low polydispersity [19].

The vast and ever-growing range of nanomaterials and nanostructures employed for therapeutic delivery are reviewed frequently [18, 20-22], and primarily consist of self-assembled aggregates formed from lipid or polymer amphiphiles (micelles, filomicelles, and vesicles), metallic nanoparticles (mainly composed of $\mathrm{Au}, \mathrm{Ag}, \mathrm{TiO}_{2}, \mathrm{ZnO}, \mathrm{CuO}$, $\mathrm{Fe}_{2} \mathrm{O}_{3}$, and $\mathrm{Fe}_{3} \mathrm{O}_{4}$ ), solid core polymeric nanoparticles of which the most common are based on the clinically relevant component poly(lactic-co-glycolic acid) (PLGA), and finally high molecular weight polymers such as poly(ethylene glycol) (PEG) dendrimers and dextran. Here, we summarize nanomaterial-based therapeutic strategies aimed at investigating and addressing cell-mediated inflammation in atherosclerosis. Considerable progress has been achieved recently in the areas of imaging, gene therapy, and immunotherapy for CVD, which will be the topics of focus in this review.

\section{Cell-Mediated Inflammation in Atherosclerosis}

\section{Inflammation in Early Lesions}

The literature has demonstrated the participation of diverse inflammatory immune cell populations during all stages of atherosclerosis [23-26]. Several recent reviews delve into the cellular and biochemical details of this process that are beyond the scope of this review [27-29], and instead we intend to present the key concepts that have guided recent nanomaterials-based therapeutic strategies. The initial step in plaque formation is believed to involve dysfunctional endothelium, which permits infiltration and entrapment of LDL within the arterial intima [30]. LDL is retained via ionic bonds with proteoglycans in the extracellular matrix and subjected to oxidative modifications by enzymes and reactive oxygen species [31]. Continued irritative stimulations of the endothelium that include hypertension, dyslipidaemia, localized oxidation, and inflammatory factors upregulate endothelial cell adhesion receptors to promote monocyte recruitment into the vessel walls $[32,33]$. Here, monocytes encounter fatty deposits and are activated by cytokines, growth factors, and modified lipid species, such as oxidized LDL (oxLDL), which drive their differentiation into lipid-laden macrophages, i.e. foam cells, and inflammatory DC populations [34]. Initially, controlled inflammation resolution is maintained by molecules including interleukin-10 (IL-10), transforming growth factor- $\beta$ (TGF $\beta$ ), lipoxins, resolvins, protectins, maresins, and prostaglandins $[27,35,36]$. This environment induces differentiation of monocytes into M2 macrophages that clear apoptotic debris 
and promote egression of inflammatory cells out of the plaque. Additionally, previously quiescent smooth muscle cells (SMCs) transition to a proliferative phenotype that expresses extracellular matrix components, generating a stabilizing fibrous cap composed primarily of fibrillar collagen that prevents plaque rupture $[37,38]$. Thus early lesions are small, asymptomatic, and stable, demonstrating inflammation characteristic of wound healing and tissue regeneration.

\section{Inflammation in Late-Stage Vulnerable Plaques}

Chronic intimal inflammation and hypercholesterolaemia can eventually lead to plaque instability, rupture and subsequent formation of a thrombus capable of occluding arteries and causing cardiac infarction. Hypercholesterolaemia promotes increased infiltration into lesions of Ly6 $\mathrm{C}^{\text {hi }}$ monocytes, which differentiate into macrophages that display an inflammatory phenotype similar to M1 macrophages (Fig. 1) [39]. Polarization towards M1 verses M2 macrophages within atheromas shifts the local inflammatory response from that of a healing/growth phenotype to that of a microbicidal/inhibitory capacity [40]. Although the accumulation of DCs within lesions has been shown to correlate with the stage of atherosclerosis, they have been found to be both atherogenic as well as atheroprotective, likely due to their heterogeneity [41-46]. Professional APCs, such as macrophages and DCs are highly phagocytic owing to their vast assortment of pattern recognition receptors (PRRs) that allow increased uptake of materials of diverse surface chemistries [47]. Although LDL uptake is regulated by a feedback system to prevent intracellular lipid overload, uptake of modified lipids including oxLDL by PRRs known as scavenger receptors can bypass this feedback to result in excessive accumulation of intracellular lipids $[48,49]$. Accumulating foam cells release inflammatory cytokines including interleukin-1 $\beta$ (IL-1 $\beta$ ) and tumor necrosis factor (TNF), further recruiting inflammatory cell populations, such as T cells, mast cells, and neutrophils. [23, $29,50,51]$. The vasa vasorum serves as a key gateway for the entrance of migrating macrophages and leukocytes, converting the vessel adventitia into what has been characterized as an organized ectopic lymphoid tissue containing diverse immune cell populations [52-55]. These cytokines and recruited immune cells result in plaque instability via increased expression of reactive oxygen species and collagendegrading metalloproteinases $[28,56,57]$. Furthermore, the progression of a secondary necrotic core composed of apoptotic cellular debris promotes the stimulation of APC intracellular PRRs toll-like receptors (TLRs) 7 and 9 by self-DNA complexes, inducing the release of pro-inflammatory $\mathrm{T}_{\mathrm{H}} 1$-biased cytokines within atheromas [58]. Development of this necrotic core is a result of defective clearance of apoptotic cells as well as disrupted chemokine-mediated guidance cues that recruit and retain inflammatory cells within lesions [27, $56,59]$. Late-stage plaques vulnerable to rupture therefore

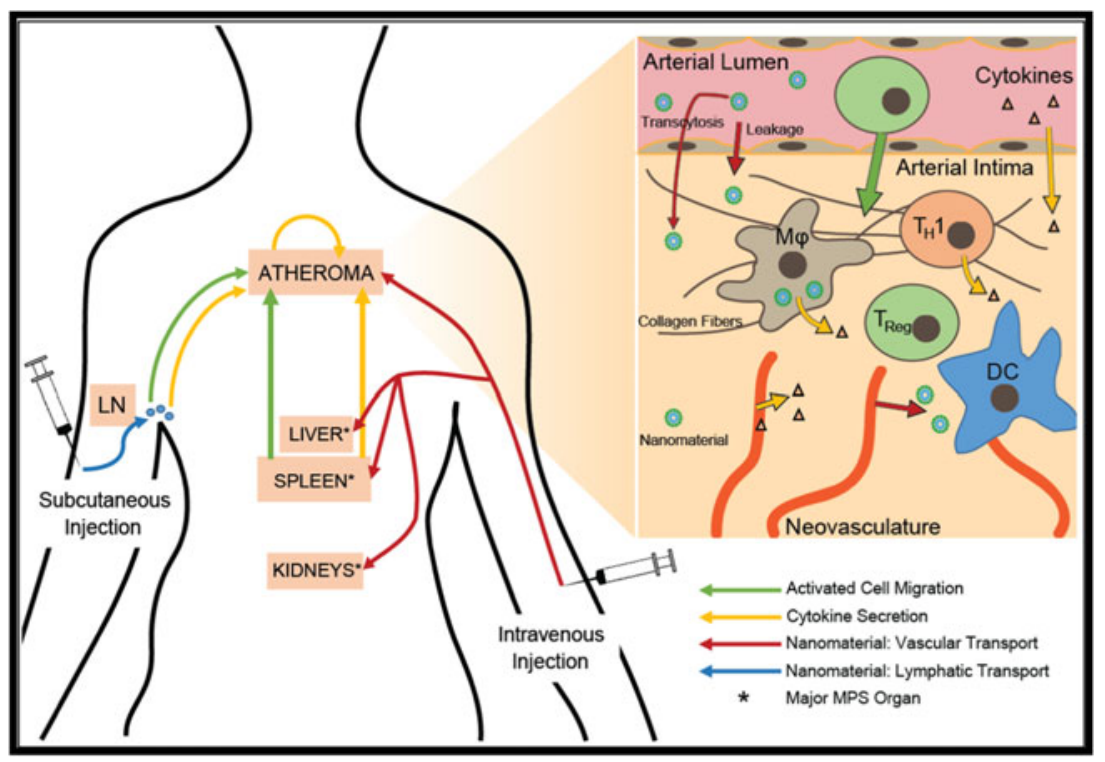

Fig. 1 Comparison of subcutaneous and intravenous routes of administration for nanomaterial-based treatment of atherosclerotic lesions. Choice in route of administration may alter nanomaterial biodistribution and the resulting immunomodulation. Subcutaneous injection is most likely to target nanomaterials to nearby lymph nodes, where they are internalized and processed by antigen-presenting cells (APCs). These cells may then activate other immune cells, promoting their trafficking to the atheroma and/or secretion of cytokines that can elicit systemic pro- or anti-inflammatory responses. Intravenous injection is more likely to result in targeting of the atheroma directly for local imaging or modulation of inflammation, but the majority of nanomaterials may be lost to phagocytic cell populations within the major organs of the mononuclear phagocyte system (MPS): the liver, spleen, and kidneys. As a secondary lymphoid organ, the spleen is a major site of nanomaterial uptake and processing by APCs. These splenocytes may activate other immune cells and/or secrete cytokines systemically, both of which can alter atheroma development and progression remotely 
result from cell-mediated pro-inflammatory responses that promote dysregulated cellular chemotaxis, tissue damage, and enzyme-induced weakening of the fibrous cap.

\section{Design Parameters for Engineering Nanomaterials That Modulate Inflammatory Cells}

\section{Cellular Interactions with Nanomaterials}

Evolutionarily driven interactions between APCs and bacterial, fungal, and viral nano- and microstructures provide a powerful opportunity for rationally designed nanomaterials to influence inflammation-driven pathologies, such as atherosclerosis. Nanomaterials are broadly defined as any material with at least one external dimension that is less than $1,000 \mathrm{~nm}$ [60], and the vast range of compounds that can be engineered within this size range presents immense opportunities to mimic the physiochemical interactions between APCs and pathogens for therapeutic applications. A diverse range of variables of course govern celluar interactions with materials that include surface chemistry, size, shape, elastic modulus, and charge (Fig. 2) $[17,18,61]$. In a broader context, these different parameters ultimately determine two critical objectives: (1) specifying the biodistribution of nanomaterials so that they reach their intended cellular targets following administration and (2) controlling the release of transported payloads from nanomaterials to achieve the desired intracellular responses. With the plethora of new nanomaterials being developed, we find these two essential criteria to be often overlooked. We therefore discuss below the influence of nanomaterial properties on biodistribution and intracellular delivery.

\section{Biodistribution}

Modulation of inflammation for the purpose of altering and reversing the progression of atherosclerosis can occur through two different, and not mutually exclusive, biodistribution paradigms. First, systemic inflammation can be altered by targeting the high concentrations of immune cells residing within secondary lymphoid organs, mainly the lymph nodes and the spleen. Second, nanomaterials can be targeted to either the plaques themselves or to immune cells that are eventually destined to traffic to the plaques, such as LyC $6^{\mathrm{hi}}$ monocytes. In both cases, subcutaneous administration is likely to deliver the nanomaterials first to lymph nodes [62]. Intravenous administration can permit targeting of atheroma, but would result in clearance of the vast majority of nanomaterials by the
Fig. 2 Size, shape, charge, and surface chemistry are important variables to consider when designing nanomaterials for the modulation of inflammatory cells
SIZE

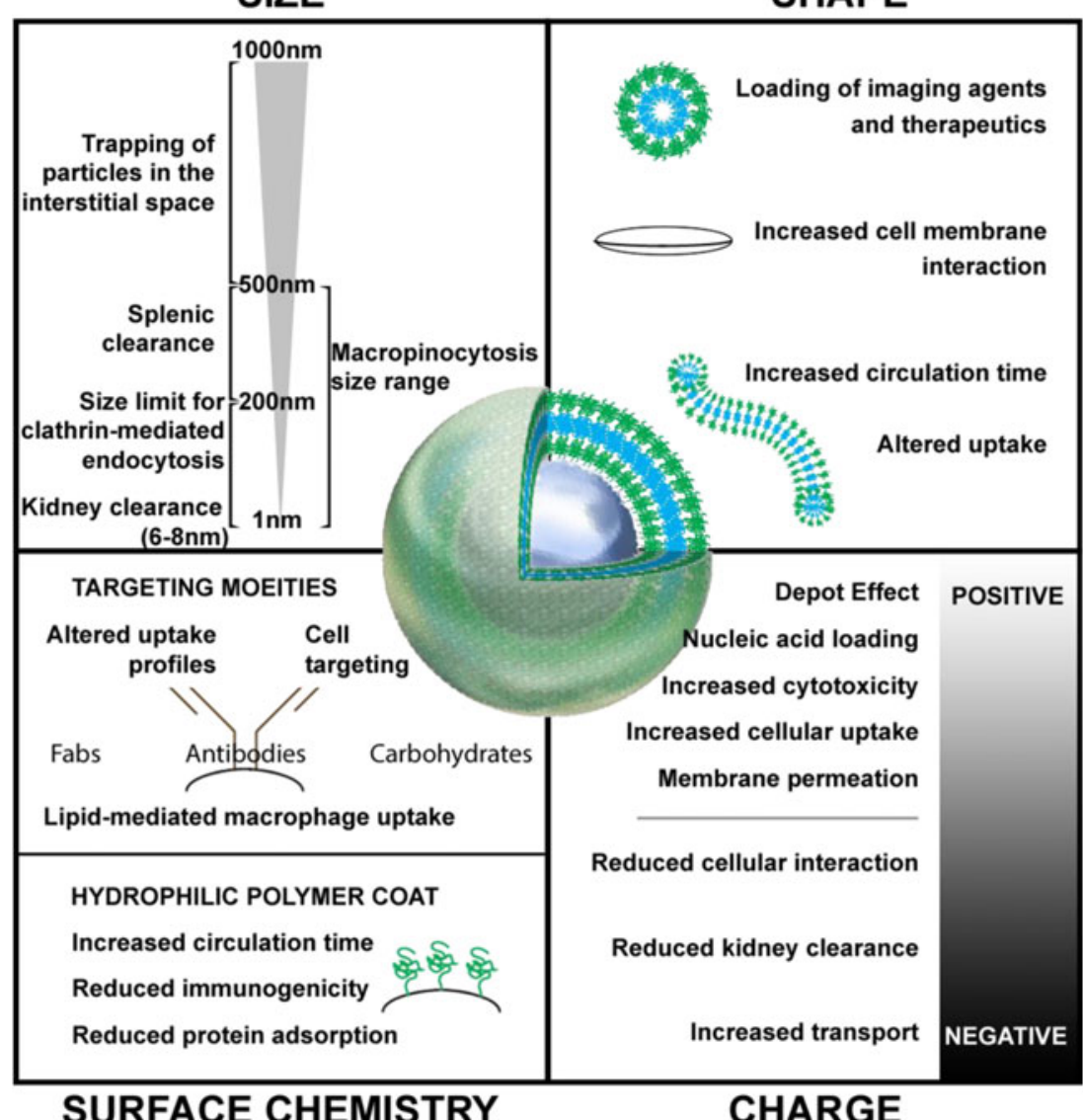

CHARGE 
MPS [63]. Clearance via the MPS can occur within the blood and interstitial space [63], or through filtration and phagocytosis within the spleen, liver [64], and kidneys [65, 66]. Surface modification of nanomaterials by PEGylation is a common practice to reduce such clearance [67], via the ability of dense poly(ethylene glycol) layers to resist protein adsorption [68], but regardless of the surface modification, the vast majority of intravenously injected nanomaterials are still cleared by the MPS [14]. In the case of delivery to plaque sites, nanomaterials will need to transit across the endothelial lining of the blood vessel to access the arterial intima (Fig. 1). As plaques often possess dysfunctional endothelium, some nanomaterials may passively enter into the arterial intima directly, without transcytosis through endothelial cells. Additionally, in more advanced plaques, significant hypoxic conditions result in the expansion of microvessels (known in healthy contexts as vasa vasorum) into the plaque. This angiogenesis results in poorly structured vessels, which can also allow for the leakage of nanomaterials into the atherosclerotic plaques [69]. Beyond passive targeting, nanomaterials can also be surface functionalized to target receptors specific to dysfunctional endothelium, thus increasing their opportunities for diffusion into the plaque, uptake by phagocytic cells, or transcytosis by endothelial cells [70-72].

\section{Mechanism of Cellular Uptake and Intracellular Delivery}

In order to enter into cells, nanomaterials can be engineered to exploit several cellular mechanisms available for the uptake of extracellular materials. Detailed descriptions of these processes can be found in numerous recent reviews [73-75], and here we summarize several mechanisms that have been used for the targeting of proatherogenic inflammatory cells. Macropinocytosis, wherein cells constitutively engulf extracellular fluids, can allow internalization of nanomaterials in a non-targeted fashion [76]. Caveolae-mediated, clathrin-mediated, and alternative endocytosis pathways appear to have size restrictions of approximately $100 \mathrm{~nm}$ or less, and often require receptor recognition to allow for internalization [77, 78]. Phagocytosis is the most size-permissive, capable of internalizing particles as large as or larger than the cell, though it also requires receptor recognition [79]. While all cells are capable of endocytosis, APCs are particularly adept at macropinocytosis and phagocytosis [80]. Nanomaterial surface charge can further enhance these membrane interactions and improve uptake. Due to the negative charge of cell membranes, positively charged nanomaterials can be attracted to, adhere to, or transit through the plasma membrane [81]. This benefit is to be weighed against the apparent cytotoxicity of cationic nanomaterials, polymers, and lipids [82]. Still, surface conjugation of nanomaterials with targeting moieties remains the most specific and promising route. Nanomaterials can be coated with whole antibodies, but smaller ligands such as individual Fab domains or single domain nanobodies have increasingly become more prevalent [46, 83-85]. A recent study using poly(lactic-coglycolic acid) (PLGA) nanomaterials compared different monoclonal antibodies, each specific for a different DC surface marker, and all targeting moieties were found to improve $\mathrm{T}$ cell responses elicited by PLGA nanoparticles [86].

\section{Nanomaterials to Enhance the Imaging of Atherosclerosis}

\section{Overview of Imaging Modalities Utilizing Nanomaterials}

The clinical diagnosis and staging of atherosclerosis currently relies on indirect markers of disease, some of which only become apparent or detectable when mid-to-late stage plaques are prevalent. As evidence grows that early intervention could be a promising way to combat the disease, it is increasingly important that detection and staging methods are developed for the purpose of accurately assessing disease state [87]. There are a number of imaging technologies currently used clinically, namely: positron emission tomography (PET), X-ray computed tomography (CT), near-infrared fluorescence (NIRF), and magnetic resonance imaging (MRI). Due to their ability to achieve targeted delivery of often low solubility fluorophores and contrast agents, nanomaterials have recently found extensive use for the enhancement of NIRF and MRI.

NIRF imaging is of growing interest within the medical and research communities. Optical imaging typically fails in vivo due to poor tissue penetrance at visible wavelengths and high autofluorescence of tissues, with NIRF sidestepping both issues due to the properties of near-infrared wavelengths. NIRF is a high-sensitivity technique, with relatively poor resolution. A variety of different nanomaterial-based delivery systems have been developed for NIRF, including fluorochrome-labeled PEG, dextran, silica, and other polymeric nanomaterials [88, 89] as well as surface-stabilized quantum dots [90, 91]. Lobatto et al. recently correlated MRI images of vascular permeability in atherosclerotic lesions with the uptake of liposomal nanoparticles conjugated to the NIRF dye Cy7 both in vivo and ex vivo [69]. This important study demonstrated that microvessels within the vasa vasorum could permit nanomaterial accumulation within atheromas. The decreased toxicity and stable signal from PEGylated quantum dots have also found utility for imaging of microvessels. The functional microcirculation deep in mouse hind limb skeletal muscle was successfully imaged by laser scanning multiphoton microscopy and fluorescent 655-nm 5,000-MW methoxy-PEGylated quantum dots [92].

MRI provides high-resolution imaging of vessels and tissues, but has relatively low sensitivity compared to PET and 
NIRF. Magnetic nanomaterials are commonly used to visualize tissues and organs and typically have a magnetic core with a hydrophilic surface coating [93]. The magnetic core is usually composed of magnetite $(\mathrm{Fe} 3 \mathrm{O} 4)$ and maghemite $(\gamma-$ $\mathrm{Fe} 2 \mathrm{O} 3)$ with a general formula of $(\mathrm{FeO}) 1-\mathrm{n}(\mathrm{Fe} 2 \mathrm{O} 3) \mathrm{n}$ [94], and often solubilized with hydrophilic polymers [95]. Additionally, conjugation or loading of nanomaterials with chelated gadolinium ions (Gd) can enhance contrast during MRI [96]. The in vivo stability of magnetic NP has been improved by different methods, including dense packing and size-shape design [97]. The ability of ultra-small superparamagnetic iron oxide particles (USPIO)-enhanced MRI was shown to differentiate benign, inflammatory lesions from malignancy [98]. Spatiotemporal mapping of SPIO nanoparticles by MRI QSM provided a reliable, rapid, noninvasive method for identifying organ-specific inflammation [99]. USPIO-enhanced MRI is feasible for in vivo assessment of vascularity and macrophage content in atherosclerotic carotid plaques, determining an association of these potential imaging biomarkers with plaque vulnerability [100]. Superparamagnetic iron oxide nanoparticles (SPIONs) as contrast agents for MRI of inflammatory processes are useful for the in vivo MRI detection of macrophage infiltration [101].

\section{Dual Modality Imaging}

While the above-mentioned imaging techniques have been successfully used alone, they are often combined for multimodal imaging, which leverages the differences in sensitivity and resolution between several distinct imaging modalities. Common combinations include PET-CT, PET-MRI, and MRI-NIRF, though other combinations have proven useful $[102,103]$. These combined imaging techniques work best if both sets of imaging probes/contrast agents have similar pharmacodynamic properties, a task made easier through conjugation to or incorporation in nanomaterials [104, 105]. Cellular fluorescence and MRI of vascular inflammation was achieved with a multi-functional high-relaxivity platform composed of iron-cobalt $(\mathrm{FeCo})$ nanoparticles with Cy5.5-conjugated graphitic-carbon (GC) shells. [106]. These FeCo/GC nanoparticles were found to accumulate in inflammatory vascular macrophages in vivo. Vascular cell adhesion molecule 1 (VCAM-1) is up-regulated in numerous inflammatory processes, including early atherosclerosis. To localize and quantify VCAM-1 expression, VCAM-1 targeted liquid perfluorocarbon nanobeacons with ${ }^{19} \mathrm{~F}$ fluorine in their cores were designed for both MR spectroscopy and imaging [107]. Additionally, tobacco mosaic virus nanoparticles engineered to target VCAM-1 were labeled with both Cy5 and chelated Gd ions for dual MRI/NIRF imaging of atherosclerotic plaques [96]. Hybrid PET/MRI of inflammatory leukocytes in murine atherosclerotic plaques was achieved using 13-nm dextran nanoparticles labeled with zirconium- 89 and NIRF fluorochrome VT680 [108]. Modulation of macrophage recruitment with RNAi-delivering nanoparticles verified that this technique could assess atherosclerotic inflammation.

\section{Nanomaterials for Gene Therapy}

\section{Nucleic Acid Delivery Via Nanomaterials}

Significant therapeutic potential exists in the controlled delivery of nucleic acids to modulate the expression of inflammatory mediators, either through transient modulation or permanent gene therapy. In both cases, the delivery of nucleic acids to target cells is required. Furthermore, the use of nucleic acids in translational medicine has a number of barriers that must be overcome. Therapeutically relevant nucleic acids are readily degraded in the extracellular space by nucleases [109], and show poor tissue penetrance. They are difficult to functionalize with targeting moieties, and are poorly endocytosed by cells [110]. Once endocytosed, nucleic acids are sequestered and degraded within the endosome and lysosome, and effective therapeutic use would require endosomal escape and translocation into either the cytosol or nucleus. All of these difficulties can be resolved through the use of nanocarriers-viral, liposomal, polymeric, or otherwise. Nucleic acids are typically negatively charged due to their phosphate backbone, and thus many of the most effective nanocarriers are composed of cationic lipids or polymers. The benefits of nanomaterial-based delivery of nucleic acids are espoused in a number of reviews and include protection from nucleases, targeted delivery, and enhanced cytosolic availability [111-114].

\section{Gene Therapies Targeting Monocytes and Macrophages}

There has been considerable success in targeting nanomaterials carrying siRNA to monocytes and macrophages. siRNA targeting of mitogen-activated protein kinase kinase kinase kinase 4 (Map4k4) resulted in reduced TNF- $\alpha$ and IL-1 $\beta$ secretion from macrophages systemically. This feat was all the more impressive as the nucleic acids were delivered orally, packaged within glucan nanoparticles [115]. Hyaluronin-stabilized liposome-based nanoparticles were targeted to leukocytes via surface-conjugated monoclonal antibodies against $\beta 7$ integrin for the delivery of cyclin D1 siRNA. These cells were blocked from proliferation, and agonist failed to result in increased secretion of type 1 cytokines, such as IL-2 and TNF- $\alpha$ [116]. Therapeutic regression of plaques can be improved by monocyte recruitment, which can shift the balance of lesion resident macrophages in favor of the non-inflammatory M2 phenotype. A seminal paper by Leuschner et al. demonstrated the systemic silencing of CCR2 within monocytes using siRNA-loaded nanoparticles, which 
resulted in a reduction of atherosclerotic lesion size [117]. Although prophylactically effective at limiting the progression of atherosclerosis, systemic silencing of CCR2 disrupts normal monocyte function and can potentially limit plaque regression during treatment for CVD [56].

Several nanomaterial formulations have taken advantage of the inherent phagocytic activity of macrophages for the in vivo delivery of microRNA mimics (miRNA or miR) and anti-miRNA (antagomir or antimir). Systemic delivery of liposomally encapsulated miRNA-181b mimics protected ApoE-/- mice from atherosclerosis [118]. miRNA-155 is notable in that it has clinical relevance in both cancer and atherosclerosis. Antagomir introduced into atherosclerotic mice via tail vein injection resulted in a decrease in plaque size [119]. Antagomir has yet to be encapsulated within nanocarriers that are targeted to specific cells within atherosclerotic plaques, though PLGA-encapsulated antagomir was tested as a lymphoma therapy [120]. That miR-155 is an important modulator in a number of cell types is further evidence that antagomir treatment should be carefully targeted to relevant cells to avoid off-target effects following systemic administration. miRNA-146a, another frequently discussed miR, reduces macrophage activation when delivered in vivo within liposomes [121]. Pluronic encapsulation and systemic introduction of antagomir to miRNA-342-5p suppresses atherosclerosis by reducing the number of macrophages and SMCs in plaques [122].

\section{Gene Therapies Targeting Vascular Endothelium and Vascular Smooth Muscle Cells}

The vascular endothelium provides a number of signals critical for the initiation and propagation of atherosclerotic inflammation. Dysfunctional endothelium is an early marker for atherosclerosis [123], and the endothelium both expresses TLRs [124] and secretes inflammatory cytokines [125]. As such, modulation of these signals could be an effective option for the treatment of CVD. Liposomes have been targeted to the vascular endothelium using conjugated antibodies specific for VCAM-1, and successfully delivered siRNA against VEcadherin to activated endothelial cells in vivo [126]. Most reports of miR and antagomir delivery to endothelial cells involve in vitro experiments or systemic application of nonencapsulated nucleic acids. For example, in vitro application of miR-221 to human umbilical vein endothelial cells resulted in inhibition of expression of AdipoR1. This resulted in increased activity of NF-kB and an increased inflammatory response, while decreasing endothelial nitric oxide production [127]. The delivery of antagomir to miR-92a via retroorbital injection in atherosclerotic mice resulted in reduced endothelial inflammation and reduced plaque size [128]. In human atherosclerosis, SMCs in the arterial intima are some of the first cells to develop into foam cells [129]. Additionally,
SMCs play a considerable role in the remodeling of the extracellular matrix in the developing atherosclerotic plaque, which can result in plaque destabilization and rupture. [130]. To combat plaque destabilization, matrix metalloproteinase-2 siRNA was encapsulated in polymeric nanostructures and was found to inhibit SMC migration in vitro, suggesting the potential to reduce atherosclerosis and restenosis [131].

\section{Nanomaterials for Immunotherapy Against Atherosclerosis}

\section{Cellular Targets for Immunotherapy}

The critical roles of both innate and adaptive immunity during inflammation suggest immunotherapy as a potential component of effective treatment regimens for CVD [132, 133]. Immunotherapies have primarily focused on manipulating APCs with an emphasis on DCs, which have been shown to influence the maturation and homeostasis of atheromas [41-43]. Furthermore, DCs have evolved to interact with viruses and can thus be targeted and manipulated by nanomaterials that mimic viral structures and functions [134-137]. Notably, the specific functions of DCs depend on their subset, as some are proatherogenic [43] and others atheroprotective [42]. Plasmacytoid DCs (pDCs) have a particularly dichotomous role, serving as the primary source of proatherogenic type I interferons (IFN) [138-141] while also playing key roles in the activation of regulatory T cells (Tregs) that stabilize plaques and prevent rupture [142, 143]. Inflammation induced by $\mathrm{pDCs}$ is an essential first step during immune responses to viral infection in both humans and mice, and a link between viral infection and atherosclerosis has long been suspected [144-146]. Interestingly, both viral- and plaque-derived factors stimulate TLRs within pDCs [58] and promote atherosclerosis through mechanisms suspected to involve natural killer T (NKT) cells [23, 147, 148]. Influences of bacterial infection have also been implicated, and Mycobacterium bovis BCG vaccination was recently found to promote an atheroprotective immunoregulatory profile in atherosclerotic mice via stimulation of pDCs [149]. These findings support targeting the immune cell component of atherosclerosis, via either vaccination or induction of tolerance, to be a viable strategy [132]. Relatively few attempts have been made to engineer nanomaterial delivery systems to enhance atheroprotective vaccination or immunotherapies, but recent work suggests that such strategies are rapidly gaining interest.

\section{Vaccination Against Heart Disease}

Vaccines for the treatment of CVD have mainly focused on injections of antigens within oxLDL, primarily oxidized 
phospholipids and peptide fragments of apoB-100 [150]. With up to a $70 \%$ decrease in atherosclerosis being reported in some studies, vaccination has proven to be a promising approach. Although not completely understood, the mechanism behind the atheroprotective effect of vaccination against oxLDL has been strongly linked to antibody generation [151]. As in standard vaccination, packaging of the antigen and adjuvant is critical, making nanomaterials a versatile platform for delivery. For example, chitosan nanoparticles served as carriers for plasmids during DNA vaccination against cholesteryl ester transfer protein (CETP) and were found to attenuate atherosclerosis in rabbits [152]. Another vaccine, HB-ATV-8, targets CETP as well, though it utilizes a synthetic peptide derived from CETP as the antigen, and is packaged within a lipid formulation $[153,154]$. This nanoparticle vaccine was shown to be effective in preclinical trials, and is entering phase 1 development. Despite the demonstrated atheroprotective effects of parenteral immunization with native LDL or LDL-derived peptides and the established benefit of using nanoparticle vehicles during immunization, few other groups have reported nanomaterial-based vaccines for CVD.

\section{Immunomodulation of Inflammatory Cells in Atherosclerosis}

Nanomaterial-based immunomodulation of inflammatory cell populations during CVD has primarily been achieved by enhancing the delivery of statins. In addition to hindering cholesterol biosynthesis and Rho-associated kinase (ROCKs) activity, statins also decrease cell-mediated inflammation by inhibiting 3-hydroxy-3-methylglutaryl-coenzyme-A (HMG$\mathrm{CoA})$ reductase $[155,156]$. Recent findings have demonstrated the benefits of the controlled delivery of statins via nanomaterials, which permit better targeting of plaqueresident inflammatory cells as well as minimizes toxic sideeffects in the liver $[157,158]$. Duivenvoorden et al. developed recombinant HDL nanoparticles loaded with simvastatin that both decreased the number of plaque-resident macrophages as well their expression of genes related to inflammation [157]. Depending on the dosage, these particles were found to inhibit progression of plaque inflammation as well as decrease inflammation in advanced atheromas. But statin delivery is only the tip of the ice berg for nanomaterials in the area of immunomodulation. As evidenced by their stimulation of immune cells during vaccination against infectious diseases, cancer immunotherapy and the induction of tolerance, nanomaterials can be engineered to target and modulate a variety of different immune cell populations. Such tools may have great potential for the treatment of CVD, but have yet to be adequately explored.

\section{Future Directions and Conclusions}

Recent advances in nanotechnology and immunology now permit the rational design of targeted nanomaterials for the therapeutic and diagnostic probing and modulation of key inflammatory cell populations contributing to CVD (Table 1). Multi-disciplinary approaches that incorporate nanomaterials into the investigation of basic biochemical and cellular mechanisms contributing to atherosclerosis may reveal novel therapeutic targets. Atherosclerotic inflammation is influenced by cytokines expressed systemically by APCs located in distal organs such as the spleen as well as by factors released locally within lesions by monocyte-derived macrophages and foam cells. Neither of these inflammatory sources is sufficiently addressed by the current clinical approaches to the treatment of CVD.

A critical weakness of current therapies for atherosclerosis is cell-mediated inflammation [11], suggesting immunotherapy as a promising new approach to treatment [132]. As discussed above, nanomaterial-enhanced vaccination and immunotherapy are up-and-coming untapped areas in need of further development. Such strategies will require new platforms engineered to target plaque-resident inflammatory cells, and several groups have recently developed nanomaterials for improved targeting of macrophages within lesions. Dextran nanoparticles were found to target macrophages within lesions because of the higher prevalence and activity of phagocytic cells within plaques and sites of inflammation [108, 159]. Synthetic HDL nanoparticles composed of PLGA and cholesteryl oleate with a triphenylphosphonium cationdecorated phospholipid bilayer coat were investigated by Marrache et al., and these HDL mimics were found to both target macrophage mitochondria and decrease lipid levels [160]. Sanchez-Gaytan et al. synthesized hybrid lipoprotein/ PLGA nanoparticles capable of both drug delivery to and imaging of plaque-resident monocytes [161]. A smart nanosystem was recently shown by $\mathrm{Oh}$ et al. to be capable of photothermal ablation of inflammatory macrophages in high-risk plaques [162].

A majority of current research focuses on the major inflammatory players in atheromas: endothelial cells, macrophages/ monocytes, dendritic cells, and SMCs. Consequently, nanomaterials designed to target the diversity of other immune populations contributing to plaque progression and instability are lacking and should be an objective of future strategies. Neutrophils and T cells are thought to play an important role in the secretion of factors within the atherosclerotic microenvironment. Neutrophils, which largely promote atherogenesis and plaque destabilization, aid in the activation of macrophages within the atheroma through the cellular release of neutrophil extracellular traps (NETs) [163]. Nanoparticles have been engineered to target neutrophils, including drugladen albumin-polystyrene nanoparticles, which were able to 


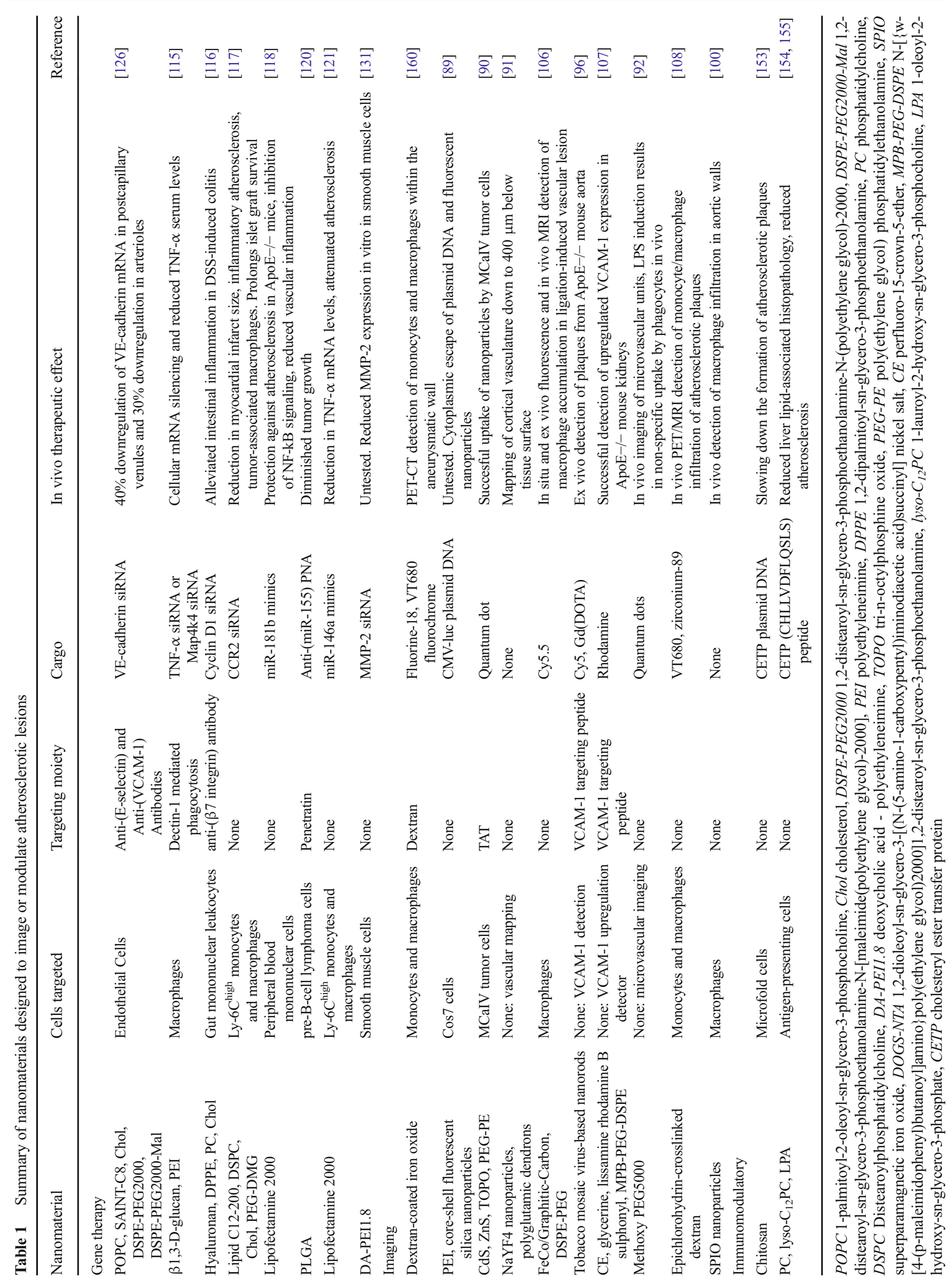


reduce the adhesion of neutrophils to endothelium in vivo. [164] This result has implications for the treatment of CVD, as reduced numbers of recruited neutrophils could result in decreased macrophage activation and lower downstream numbers of recruited inflammatory cells, such as $\mathrm{T}_{\mathrm{H}} 17$ cells. $\mathrm{T}_{\mathrm{H}} 17$ cells, along with $\mathrm{T}_{\mathrm{H}} 1$ cells, are known to also contribute to atherogenesis through the secretion of pro-inflammatory cytokines. Nanoparticles can be targeted to T cells using surface-conjugated antibodies, such as PLGA nanoparticles with anti-CD4 antibodies. These nanoparticles, loaded with LIF, were found to shift CD4+ T cells toward Treg development and away from $\mathrm{T}_{\mathrm{H}} 17$ development in vitro and in vivo following ex vivo pretreatment of T cells [165]. Another potential source of atherosclerotic inflammation is NKT cell activation due to heightened type I interferon (IFN) levels [23, 147, 148]. TLR9-induced type I IFN, IL-12, and IL-18 expression from pDCs is essential for NK cell function during inflammation $[166,167]$ and may activate and recruit invariant NKT (iNKT) cells [23, 168-170], which are proatherogenic immune cell population within lesions [23]. Although the biology of NKT cells is poorly characterized and their role in the progression of atherosclerosis remains controversial, they may emerge as promising targets for future immunotherapies against CVD.

In addition to using imaging modalities to assess plaque progression and vulnerability, future approaches will utilize nanomaterials to enhance other techniques for early detection. For example, proteomics has shown promise for the identification of molecular indicators of disease, and nanomaterials can enhance purification and isolation of these markers from tissues and fluids. Stubiger et al. recently examined superparamagnetic $\mathrm{Fe}_{3} \mathrm{O}_{4}$ nanoparticles of diverse surface chemistries that facilitate sample preparation for detection of oxidized phospholipids using MALDI-MS [171]. Nanoparticles with dimethylamine-co-epichlorohydrin-coethylenediamine functionalized surfaces allowed quantification of increased levels of oxidized phosopholipids in the plasma of ApoE-/- mice fed with high-fat diets.

Current clinical treatments for atherosclerosis focus on lowering serum levels of LDL using therapeutics such as statins, administration of antithrombotic drugs, and surgical intervention. As with many complex pathologies, a single treatment strategy is not sufficient, and CVD remains the leading cause of death worldwide. With the aid of nanomaterials, novel approaches have recently emerged that permit targeting, imaging and manipulation of inflammatory cells within atherosclerotic lesions. There are early reports of clinical success in the use of nanoparticles for applications related to atherosclerosis. Work using silica-gold nanoparticles administered via an on-artery patch and plasmonic photothermal therapy has been demonstrated to reduce plaque burden in a 180 individual clinical trial [172]. This trial also utilized an alternative delivery mechanism in the form of magnetic microbubbles that were targeted to lesions. Pre-clinical work on the intravenous delivery of proresolving peptide Ac2-26 attached to PLGA-PEG nanoparticles has been promising, showing an increase in atheroprotective properties and a decrease in oxidative stress and necrosis in LDLR-/- mice [173]. Successful future therapies will likely combine the aforementioned clinically tested strategies with new approaches that focus on controlling cell-mediated inflammation. Rationally engineered nanomaterials have already demonstrated efficacy as platforms for cancer immunotherapy and vaccination against infectious diseases, and similar strategies may provide new opportunities for the treatment of CVD.

\section{References}

1. Heidenreich PA, Trogdon JG, Khavjou OA, Butler J, Dracup K, Ezekowitz MD, et al. Forecasting the future of cardiovascular disease in the United States: a policy statement from the American Heart Association. Circulation. 2011;123:933-44.

2. Keys A, Kimura N, Kusukawa A, Bronte-Stewart B, Larsen N, Keys MH. Lessons from serum cholesterol studies in Japan, Hawaii and Los Angeles. Ann Intern Med. 1958;48:83-94.

3. Keys A. Wine, garlic, and CHD in seven countries. Lancet. 1980;1:145-6.

4. Cohen JC, Boerwinkle E, Mosley Jr TH, Hobbs HH. Sequence variations in PCSK9, low LDL, and protection against coronary heart disease. N Engl J Med. 2006;354:1264-72.

5. Horton JD, Cohen JC, Hobbs HH. PCSK9: a convertase that coordinates LDL catabolism. J Lipid Res. 2009;50(Suppl):S172-7.

6. Randomised trial of cholesterol lowering in 4444 patients with coronary heart disease: the Scandinavian Simvastatin Survival Study (4S). Lancet. 1994;344:1383-9.

7. Goldstein JL, Brown MS. The low-density lipoprotein pathway and its relation to atherosclerosis. Annu Rev Biochem. 1977;46: 897-930.

8. Colantonio LD, Bittner V, Reynolds K, Levitan EB, Rosenson RS, Banach M, et al. Association of Serum Lipids and Coronary Heart Disease in Contemporary Observational Studies. Circulation. 2016;133:256-64.

9. Strong JP, Malcom GT, Oalmann MC, Wissler RW. The PDAY Study: natural history, risk factors, and pathobiology. Pathobiological Determinants of Atherosclerosis in Youth. Ann N Y Acad Sci. 1997;811:226-35. discussion 35-7.

10. Hansson GK. Inflammation, atherosclerosis, and coronary artery disease. N Engl J Med. 2005;352:1685-95.

11. Charo IF, Taub R. Anti-inflammatory therapeutics for the treatment of atherosclerosis. Nat Rev Drug Discov. 2011;10:365-76.

12. Ridker PM, Howard CP, Walter V, Everett B, Libby P, Hensen J, et al. Effects of interleukin-1beta inhibition with canakinumab on hemoglobin A1c, lipids, C-reactive protein, interleukin-6, and fibrinogen: a phase IIb randomized, placebo-controlled trial. Circulation. 2012;126:2739-48.

13. Trombetta ES, Mellman I. Cell biology of antigen processing in vitro and in vivo. Annu Rev Immunol. 2005;23:975-1028.

14. Albanese A, Tang PS, Chan WC. The effect of nanoparticle size, shape, and surface chemistry on biological systems. Annu Rev Biomed Eng. 2012;14:1-16. 
15. Owens 3rd DE, Peppas NA. Opsonization, biodistribution, and pharmacokinetics of polymeric nanoparticles. Int J Pharm. 2006;307:93-102.

16. van Furth R, Cohn ZA, Hirsch JG, Humphrey JH, Spector WG, Langevoort HL. The mononuclear phagocyte system: a new classification of macrophages, monocytes, and their precursor cells. Bull World Health Organ. 1972;46:845-52.

17. Hubbell JA, Thomas SN, Swartz MA. Materials engineering for immunomodulation. Nature. 2009;462:449-60.

18. Moon JJ, Huang B, Irvine DJ. Engineering nano- and microparticles to tune immunity. Adv Mater. 2012;24:3724-46.

19. Van Antwerpen R, Gilkey JC. Cryo-electron microscopy reveals human low density lipoprotein substructure. J Lipid Res. 1994;35: 2223-31.

20. Getts DR, Shea LD, Miller SD, King NJ. Harnessing nanoparticles for immune modulation. Trends Immunol. 2015;36:419-27.

21. Petrarca C, Clemente E, Amato V, Pedata P, Sabbioni E, Bernardini G, et al. Engineered metal based nanoparticles and innate immunity. Clin Mol Allergy: CMA. 2015;13:13.

22. Smith DM, Simon JK, Baker Jr JR. Applications of nanotechnology for immunology. Nat Rev Immunol. 2013;13:592-605.

23. Getz GS, Vanderlaan PA, Reardon CA. Natural killer T cells in lipoprotein metabolism and atherosclerosis. Thromb Haemost. 2011;106:814-9.

24. Wang X, Ria M, Kelmenson PM, Eriksson P, Higgins DC, Samnegard A, et al. Positional identification of TNFSF4, encoding OX40 ligand, as a gene that influences atherosclerosis susceptibility. Nat Genet. 2005;37:365-72.

25. Ait-Oufella H, Salomon BL, Potteaux S, Robertson AK, Gourdy P, Zoll J, et al. Natural regulatory T cells control the development of atherosclerosis in mice. Nat Med. 2006;12:178-80.

26. Paulson KE, Zhu SN, Chen M, Nurmohamed S, Jongstra-Bilen J, Cybulsky MI. Resident intimal dendritic cells accumulate lipid and contribute to the initiation of atherosclerosis. Circ Res. 2010;106:383-90.

27. Tabas I. Macrophage death and defective inflammation resolution in atherosclerosis. Nat Rev Immunol. 2010;10:36-46.

28. Hansson GK, Libby P, Tabas I. Inflammation and plaque vulnerability. J Intern Med. 2015;278(5):483-93.

29. Hansson GK, Hermansson A. The immune system in atherosclerosis. Nat Immunol. 2011;12:204-12.

30. Tabas I, Williams KJ, Boren J. Subendothelial lipoprotein retention as the initiating process in atherosclerosis: update and therapeutic implications. Circulation. 2007;116:1832-44.

31. Skalen K, Gustafsson M, Rydberg EK, Hulten LM, Wiklund O, Innerarity TL, et al. Subendothelial retention of atherogenic lipoproteins in early atherosclerosis. Nature. 2002;417:750-4.

32. Cernuda-Morollon E, Ridley AJ. Rho GTPases and leukocyte adhesion receptor expression and function in endothelial cells. Circ Res. 2006;98:757-67.

33. Bevilacqua MP, Pober JS, Wheeler ME, Cotran RS, Gimbrone Jr MA. Interleukin 1 acts on cultured human vascular endothelium to increase the adhesion of polymorphonuclear leukocytes, monocytes, and related leukocyte cell lines. J Clin Invest. 1985;76: 2003-11.

34. Escate R, Padro T, Badimon L. LDL accelerates monocyte to macrophage differentiation: effects on adhesion and anoikis. Atherosclerosis. 2016;246:177-86.

35. Mosser DM, Zhang X. Interleukin-10: new perspectives on an old cytokine. Immunol Rev. 2008;226:205-18.

36. Serhan CN, Chiang N, Van Dyke TE. Resolving inflammation: dual anti-inflammatory and pro-resolution lipid mediators. Nat Rev Immunol. 2008;8:349-61.

37. Campbell JH, Campbell GR. The role of smooth muscle cells in atherosclerosis. Curr Opin Lipidol. 1994;5:323-30.
38. Adiguzel E, Ahmad PJ, Franco C, Bendeck MP. Collagens in the progression and complications of atherosclerosis. Vasc Med. 2009;14:73-89.

39. Swirski FK, Libby P, Aikawa E, Alcaide P, Luscinskas FW, Weissleder R, et al. Ly-6Chi monocytes dominate hypercholesterolemia-associated monocytosis and give rise to macrophages in atheromata. J Clin Invest. 2007;117:195-205.

40. Italiani P, Boraschi D. From monocytes to M1/M2 macrophages: phenotypical vs. functional differentiation. Front Immunol. 2014;5:514.

41. Jongstra-Bilen J, Haidari M, Zhu SN, Chen M, Guha D, Cybulsky MI. Low-grade chronic inflammation in regions of the normal mouse arterial intima predisposed to atherosclerosis. J Exp Med. 2006;203:2073-83.

42. Gautier EL, Huby T, Saint-Charles F, Ouzilleau B, Pirault J, Deswaerte V, et al. Conventional dendritic cells at the crossroads between immunity and cholesterol homeostasis in atherosclerosis. Circulation. 2009;119:2367-75.

43. Weber C, M eiler S, Doring Y, Koch M, Drechsler M, Megens RT, et al. CCL17-expressing dendritic cells drive atherosclerosis by restraining regulatory $\mathrm{T}$ cell homeostasis in mice. J Clin Invest. 2011;121:2898-910.

44. Bobryshev YV. Dendritic cells and their role in atherogenesis. Lab Investig J Tech Methods Pathol. 2010;90:970-84.

45. Niessner A, Weyand CM. Dendritic cells in atherosclerotic disease. Clin Immunol. 2010;134:25-32.

46. Van de Broek B, Devoogdt N, D'Hollander A, Gijs HL, Jans K, Lagae L, et al. Specific cell targeting with nanobody conjugated branched gold nanoparticles for photothermal therapy. ACS Nano. 2011;5:4319-28.

47. Takeuchi O, Akira S. Pattern recognition receptors and inflammation. Cell. 2010;140:805-20.

48. Goldstein JL, Ho YK, Basu SK, Brown MS. Binding site on macrophages that mediates uptake and degradation of acetylated low density lipoprotein, producing massive cholesterol deposition. Proc Natl Acad Sci U S A. 1979;76:333-7.

49. Kzhyshkowska J, Neyen C, Gordon S. Role of macrophage scavenger receptors in atherosclerosis. Immunobiology. 2012;217: 492-502.

50. Liu J, Divoux A, Sun J, Zhang J, Clement K, Glickman JN, et al. Genetic deficiency and pharmacological stabilization of mast cells reduce diet-induced obesity and diabetes in mice. Nat Med. 2009;15:940-5.

51. Zernecke A, Bot I, Djalali-Talab Y, Shagdarsuren E, Bidzhekov K, Meiler S, et al. Protective role of CXC receptor 4/CXC ligand 12 unveils the importance of neutrophils in atherosclerosis. Circ Res. 2008;102:209-17.

52. Majesky MW, Dong XR, Hoglund V, Mahoney Jr WM, Daum G. The adventitia: a dynamic interface containing resident progenitor cells. Arterioscler Thromb Vasc Biol. 2011;31:1530-9.

53. Akhavanpoor M, Wangler S, Gleissner CA, Korosoglou G, Katus HA, Erbel C. Adventitial inflammation and its interaction with intimal atherosclerotic lesions. Front Physiol. 2014;5:296.

54. Campbell KA, Lipinski MJ, Doran AC, Skaflen MD, Fuster V, McNamara CA. Lymphocytes and the adventitial immune response in atherosclerosis. Circ Res. 2012;110:889-900.

55. Grabner R, Lotzer K, Dopping S, Hildner M, Radke D, Beer M, et al. Lymphotoxin beta receptor signaling promotes tertiary lymphoid organogenesis in the aorta adventitia of aged ApoE-/mice. J Exp Med. 2009;206:233-48.

56. Moore KJ, Sheedy FJ, Fisher EA. Macrophages in atherosclerosis: a dynamic balance. Nat Rev Immunol. 2013;13:709-21.

57. Saren P, Welgus HG, Kovanen PT. TNF-alpha and IL-1 beta selectively induce expression of $92-\mathrm{kDa}$ gelatinase by human macrophages. J Immunol. 1996;157:4159-65. 
58. Doring Y, Manthey HD, Drechsler M, Lievens D, Megens RT, Soehnlein O, et al. Auto-antigenic protein-DNA complexes stimulate plasmacytoid dendritic cells to promote atherosclerosis. Circulation. 2012;125:1673-83.

59. van Gils JM, Ramkhelawon B, Fernandes L, Stewart MC, Guo L, Seibert T, et al. Endothelial expression of guidance cues in vessel wall homeostasis dysregulation under proatherosclerotic conditions. Arterioscler Thromb Vasc Biol. 2013;33:911-9.

60. Buzea C, Pacheco II, Robbie K. Nanomaterials and nanoparticles: sources and toxicity. Biointerphases. 2007;2:MR17-71.

61. Yan S, Gu W, Xu ZP. Re-considering how particle size and other properties of antigen-adjuvant complexes impact on the immune responses. J Colloid Interface Sci. 2013;395:1-10.

62. Allen TM, Hansen CB, Guo LS. Subcutaneous administration of liposomes: a comparison with the intravenous and intraperitoneal routes of injection. Biochim Biophys Acta. 1993;1150:9-16.

63. Haniffa M, Bigley V, Collin M. Human mononuclear phagocyte system reunited. Semin Cell Dev Biol. 2015;41:59-69.

64. Strauss O, Dunbar PR, Bartlett A, Phillips A. The immunophenotype of antigen presenting cells of the mononuclear phagocyte system in normal human liver-a systematic review. J Hepatol. 2015;62:458-68.

65. Nelson PJ, Rees AJ, Griffin MD, Hughes J, Kurts C, Duffield J. The renal mononuclear phagocytic system. J Am Soc Nephrol. 2012;23:194-203.

66. Gottschalk C, Kurts C. The debate about dendritic cells and macrophages in the kidney. Front Immunol. 2015;6:435.

67. Jokerst JV, Lobovkina T, Zare RN, Gambhir SS. Nanoparticle PEGylation for imaging and therapy. Nanomedicine (London, England). 2011;6:715-28.

68. Jeon SI, Lee JH, Andrade JD, De Gennes PG. Protein-surface interactions in the presence of polyethylene oxide. J Colloid Interface Sci. 1991;142:149-58.

69. Lobatto ME, Calcagno C, Millon A, Senders ML, Fay F, Robson $\mathrm{PM}$, et al. Atherosclerotic plaque targeting mechanism of longcirculating nanoparticles established by multimodal imaging. ACS Nano. 2015;9:1837-47.

70. Park K, Hong HY, Moon HJ, Lee BH, Kim IS, Kwon IC, et al. A new atherosclerotic lesion probe based on hydrophobically modified chitosan nanoparticles functionalized by the atherosclerotic plaque targeted peptides. J Control Release. 2008;128:217-23.

71. Winter PM, Neubauer AM, Caruthers SD, Harris TD, Robertson JD, Williams TA, et al. Endothelial alpha(v)beta3 integrin-targeted fumagillin nanoparticles inhibit angiogenesis in atherosclerosis. Arterioscler Thromb Vasc Biol. 2006;26:2103-9.

72. Li D, Patel AR, Klibanov AL, Kramer CM, Ruiz M, Kang BY, et al. Molecular imaging of atherosclerotic plaques targeted to oxidized LDL receptor LOX-1 by SPECT/CT and magnetic resonance. Circ Cardiovasc Imaging. 2010;3:464-72.

73. Canton I, Battaglia G. Endocytosis at the nanoscale. Chem Soc Rev. 2012;41:2718-39.

74. Akinc A, Battaglia G. Exploiting endocytosis for nanomedicines. Cold Spring Harb Perspect Biol. 2013;5:a016980.

75. Oh N, Park JH. Endocytosis and exocytosis of nanoparticles in mammalian cells. Int J Nanomedicine. 2014;9 Suppl 1:51-63.

76. Swanson JA, Watts C. Macropinocytosis. Trends Cell Biol. 1995;5:424-8.

77. Bareford LM, Swaan PW. Endocytic mechanisms for targeted drug delivery. Adv Drug Deliv Rev. 2007;59:748-58.

78. Petros RA, DeSimone JM. Strategies in the design of nanoparticles for therapeutic applications. Nat Rev Drug Discov. 2010;9: 615-27.

79. Freeman SA, Grinstein S. Phagocytosis: receptors, signal integration, and the cytoskeleton. Immunol Rev. 2014;262:193-215.

80. Doherty GJ, McMahon HT. Mechanisms of endocytosis. Annu Rev Biochem. 2009;78:857-902.
81. Verma A, Stellacci F. Effect of surface properties on nanoparticlecell interactions. Small. 2010;6:12-21.

82. Kedmi R, Ben-Arie N, Peer D. The systemic toxicity of positively charged lipid nanoparticles and the role of Toll-like receptor 4 in immune activation. Biomaterials. 2010;31:6867-75.

83. Rund LA, Cho BK, Manning TC, Holler PD, Roy EJ, Kranz DM. Bispecific agents target endogenous murine T cells against human tumor xenografts. Int J Cancer. 1999;83:141-9.

84. Altintas I, Heukers R, van der Meel R, Lacombe M, Amidi M, van Bergen En Henegouwen PM, et al. Nanobody-albumin nanoparticles (NANAPs) for the delivery of a multikinase inhibitor 17864 to EGFR overexpressing tumor cells. J Control Release. 2013;165:110-8.

85. Muyldermans S. Nanobodies: natural single-domain antibodies. Annu Rev Biochem. 2013;82:775-97.

86. Cruz LJ, Rosalia RA, Kleinovink JW, Rueda F, Lowik CW, Ossendorp F. Targeting nanoparticles to CD40, DEC-205 or CD11c molecules on dendritic cells for efficient CD8(+) T cell response: a comparative study. J Control Release. 2014;192: 209-18.

87. Mulder WJ, Jaffer FA, Fayad ZA, Nahrendorf M. Imaging and nanomedicine in inflammatory atherosclerosis. Sci Transl Med. 2014;6:239sr1.

88. Jaulin N, Appel M, Passirani C, Barratt G, Labarre D. Reduction of the uptake by a macrophagic cell line of nanoparticles bearing heparin or dextran covalently bound to poly(methyl methacrylate). J Drug Target. 2000;8:165-72.

89. Fuller JE, Zugates GT, Ferreira LS, Ow HS, Nguyen NN, Wiesner $\mathrm{UB}$, et al. Intracellular delivery of core-shell fluorescent silica nanoparticles. Biomaterials. 2008;29:1526-32.

90. Stroh M, Zimmer JP, Duda DG, Levchenko TS, Cohen KS, Brown EB, et al. Quantum dots spectrally distinguish multiple species within the tumor milieu in vivo. Nat Med. 2005;11:67882.

91. Esipova TV, Ye X, Collins JE, Sakadzic S, Mandeville ET, Murray $\mathrm{CB}$, et al. Dendritic upconverting nanoparticles enable in vivo multiphoton microscopy with low-power continuous wave sources. Proc Natl Acad Sci U S A. 2012;109:20826-31.

92. Bateman RM, Hodgson KC, Kohli K, Knight D, Walley KR. Endotoxemia increases the clearance of mPEGylated 5000-MW quantum dots as revealed by multiphoton microvascular imaging. J Biomed Opt. 2007;12:064005.

93. Colombo M, Carregal-Romero S, Casula MF, Gutierrez L, Morales MP, Bohm IB, et al. Biological applications of magnetic nanoparticles. Chem Soc Rev. 2012;41:4306-34.

94. Chourpa I, Douziech-Eyrolles L, Ngaboni-Okassa L, Fouquenet JF, Cohen-Jonathan S, Souce M, et al. Molecular composition of iron oxide nanoparticles, precursors for magnetic drug targeting, as characterized by confocal Raman microspectroscopy. Analyst. 2005;130:1395-403.

95. Gupta AK, Gupta M. Synthesis and surface engineering of iron oxide nanoparticles for biomedical applications. Biomaterials. 2005;26:3995-4021.

96. Bruckman MA, Jiang K, Simpson EJ, Randolph LN, Luyt LG, Yu $\mathrm{X}$, et al. Dual-modal magnetic resonance and fluorescence imaging of atherosclerotic plaques in vivo using VCAM-1 targeted tobacco mosaic virus. Nano Lett. 2014;14:1551-8.

97. Weissleder R, Nahrendorf M, Pittet MJ. Imaging macrophages with nanoparticles. Nat Mater. 2014;13:125-38.

98. Seyfer P, Pagenstecher A, Mandic R, Klose KJ, Heverhagen JT. Cancer and inflammation: differentiation by USPIO-enhanced MR imaging. J Magn Reson Imaging: JMRI. 2014;39:665-72.

99. Wong R, Chen X, Wang Y, Hu X, Jin MM. Visualizing and quantifying acute inflammation using ICAM-1 specific nanoparticles and MRI quantitative susceptibility mapping. Ann Biomed Eng. 2012;40:1328-38. 
100. Metz S, Beer AJ, Settles M, Pelisek J, Botnar RM, Rummeny EJ, et al. Characterization of carotid artery plaques with USPIOenhanced MRI: assessment of inflammation and vascularity as in vivo imaging biomarkers for plaque vulnerability. Int J Cardiovasc Imaging. 2011;27:901-12.

101. Neuwelt A, Sidhu N, Hu CA, Mlady G, Eberhardt SC, Sillerud LO. Iron-based superparamagnetic nanoparticle contrast agents for MRI of infection and inflammation. AJR Am J Roentgenol. 2015;204:W302-13

102. Lee S, Chen X. Dual-modality probes for in vivo molecular imaging. Mol Imaging. 2009;8:87-100.

103. Azhdarinia A, Ghosh P, Ghosh S, Wilganowski N, Sevick-Muraca EM. Dual-labeling strategies for nuclear and fluorescence molecular imaging: a review and analysis. Mol Imaging Biol. 2012;14: 261-76.

104. Jennings LE, Long NJ. 'Two is better than one' - probes for dualmodality molecular imaging. Chem Commun (Camb). 2009;24: 3511-24.

105. Lee DE, Koo H, Sun IC, Ryu JH, Kim K, Kwon IC. Multifunctional nanoparticles for multimodal imaging and theragnosis. Chem Soc Rev. 2012;41:2656-72.

106. Kosuge H, Sherlock SP, Kitagawa T, Terashima M, Barral JK, Nishimura DG, et al. FeCo/graphite nanocrystals for multimodality imaging of experimental vascular inflammation. PLoS One. 2011;6:e14523.

107. Southworth R, Kaneda M, Chen J, Zhang L, Zhang H, Yang X, et al. Renal vascular inflammation induced by Western diet in ApoEnull mice quantified by (19)F NMR of VCAM-1 targeted nanobeacons. Nanomedicine. 2009;5:359-67.

108. Majmudar MD, Yoo J, Keliher EJ, Truelove JJ, Iwamoto Y, Sena $\mathrm{B}$, et al. Polymeric nanoparticle PET/MR imaging allows macrophage detection in atherosclerotic plaques. Circ Res. 2013;112: 755-61.

109. Kawabata K, Takakura Y, Hashida M. The fate of plasmid DNA after intravenous injection in mice: involvement of scavenger receptors in its hepatic uptake. Pharm Res. 1995;12:825-30.

110. Wolff JA, Budker V. The mechanism of naked DNA uptake and expression. Adv Genet. 2005;54:3-20.

111. Vercauteren D, Rejman J, Martens TF, Demeester J, De Smedt SC, Braeckmans K. On the cellular processing of non-viral nanomedicines for nucleic acid delivery: mechanisms and methods. J Control Release. 2012;161:566-81.

112. Elsabahy M, Nazarali A, Foldvari M. Non-viral nucleic acid delivery: key challenges and future directions. Curr Drug Deliv. 2011;8:235-44

113. Ding Y, Jiang Z, Saha K, Kim CS, Kim ST, Landis RF, et al. Gold nanoparticles for nucleic acid delivery. Mol Ther. 2014;22:107583.

114. Nguyen J, Szoka FC. Nucleic acid delivery: the missing pieces of the puzzle? Acc Chem Res. 2012;45:1153-62.

115. Aouadi M, Tesz GJ, Nicoloro SM, Wang M, Chouinard M, Soto E, et al. Orally delivered siRNA targeting macrophage Map4k4 suppresses systemic inflammation. Nature. 2009;458:1180-4.

116. Peer D, Park EJ, Morishita Y, Carman CV, Shimaoka M. Systemic leukocyte-directed siRNA delivery revealing cyclin D1 as an antiinflammatory target. Science. 2008;319:627-30.

117. Leuschner F, Dutta P, Gorbatov R, Novobrantseva TI, Donahoe JS, Courties G, et al. Therapeutic siRNA silencing in inflammatory monocytes in mice. Nat Biotechnol. 2011;29:1005-10.

118. Sun X, He S, Wara AK, Icli B, Shvartz E, Tesmenitsky Y, et al. Systemic delivery of microRNA-181b inhibits nuclear factorkappaB activation, vascular inflammation, and atherosclerosis in apolipoprotein E-deficient mice. Circ Res. 2014;114:32-40.

119. Yang Y, Yang L, Liang X, Zhu G. MicroRNA-155 Promotes Atherosclerosis Inflammation via Targeting SOCS1. Cell Physiol Biochem. 2015;36:1371-81.
120. Babar IA, Cheng CJ, Booth CJ, Liang X, Weidhaas JB, Saltzman WM, et al. Nanoparticle-based therapy in an in vivo microRNA155 (miR-155)-dependent mouse model of lymphoma. Proc Natl Acad Sci U S A. 2012;109:E1695-704.

121. Li K, Ching D, Luk FS, Raffai RL. Apolipoprotein E enhances microRNA-146a in monocytes and macrophages to suppress nuclear factor-kappaB-driven inflammation and atherosclerosis. Circ Res. 2015;117:e1-11.

122. Wei Y, Nazari-Jahantigh M, Chan L, Zhu M, Heyll K, CorbalanCampos J, et al. The microRNA-342-5p fosters inflammatory macrophage activation through an Akt1- and microRNA-155dependent pathway during atherosclerosis. Circulation. 2013;127:1609-19.

123. Davignon J, Ganz P. Role of endothelial dysfunction in atherosclerosis. Circulation. 2004;109:III27-32.

124. Edfeldt K, Swedenborg J, Hansson GK, Yan ZQ. Expression of toll-like receptors in human atherosclerotic lesions: a possible pathway for plaque activation. Circulation. 2002;105:1158-61.

125. Sima AV, Stancu CS, Simionescu M. Vascular endothelium in atherosclerosis. Cell Tissue Res. 2009;335:191-203.

126. Kowalski PS, Zwiers PJ, Morselt HW, Kuldo JM, Leus NG, Ruiters MH, et al. Anti-VCAM-1 SAINT-O-Somes enable endothelial-specific delivery of siRNA and downregulation of inflammatory genes in activated endothelium in vivo. J Control Release. 2014;176:64-75.

127. Chen CF, Huang J, Li H, Zhang C, Huang X, Tong G, et al. MicroRNA-221 regulates endothelial nitric oxide production and inflammatory response by targeting adiponectin receptor 1 . Gene. 2015;565:246-51.

128. Loyer X, Potteaux S, Vion AC, Guerin CL, Boulkroun S, Rautou PE, et al. Inhibition of microRNA-92a prevents endothelial dysfunction and atherosclerosis in mice. Circ Res. 2014;114:434 43.

129. Allahverdian S, Pannu PS, Francis GA. Contribution of monocyte-derived macrophages and smooth muscle cells to arterial foam cell formation. Cardiovasc Res. 2012;95:165-72.

130. Feil S, Fehrenbacher B, Lukowski R, Essmann F, Schulze-Osthoff $\mathrm{K}$, Schaller M, et al. Transdifferentiation of vascular smooth muscle cells to macrophage-like cells during atherogenesis. Circ Res. 2014;115:662-7.

131. Kim D, Lee D, Jang YL, Chae SY, Choi D, Jeong JH, et al. Facial amphipathic deoxycholic acid-modified polyethyleneimine for efficient MMP-2 siRNA delivery in vascular smooth muscle cells. Eur J Pharm Biopharm. 2012;81:14-23.

132. Lichtman AH, Binder CJ, Tsimikas S, Witztum JL. Adaptive immunity in atherogenesis: new insights and therapeutic approaches. J Clin Invest. 2013;123:27-36.

133. Packard RR, Lichtman AH, Libby P. Innate and adaptive immunity in atherosclerosis. Semin Immunopathol. 2009;31:5-22.

134. Scott EA, Stano A, Gillard M, Maio-Liu AC, Swartz MA, Hubbell JA. Dendritic cell activation and T cell priming with adjuvant- and antigen-loaded oxidation-sensitive polymersomes. Biomaterials. 2012;33:6211-9.

135. Stano A, Scott EA, Dane KY, Swartz MA, Hubbell JA. Tunable T cell immunity towards a protein antigen using polymersomes vs. solid-core nanoparticles. Biomaterials. 2013;34:4339-46.

136. Vasdekis AE, Scott EA, O’Neil CP, Psaltis D, Hubbell JA. Precision intracellular delivery based on optofluidic polymersome rupture. ACS Nano. 2012;6:7850-7.

137. Cerritelli S, O'Neil CP, Velluto D, Fontana A, Adrian M, Dubochet J, et al. Aggregation behavior of poly(ethylene glycolbl-propylene sulfide) di- and triblock copolymers in aqueous solution. Langmuir. 2009;25:11328-35.

138. Levy Z, Rachmani R, Trestman S, Dvir A, Shaish A, Ravid M, et al. Low-dose interferon-alpha accelerates atherosclerosis in an LDL receptor-deficient mouse model. Eur J Int Med. 2003;14: 479-83. 
139. Cella M, Facchetti F, Lanzavecchia A, Colonna M. Plasmacytoid dendritic cells activated by influenza virus and CD40L drive a potent TH1 polarization. Nat Immunol. 2000;1:305-10.

140. Macal M, Lewis GM, Kunz S, Flavell R, Harker JA, Zuniga EI. Plasmacytoid dendritic cells are productively infected and activated through TLR-7 early after arenavirus infection. Cell Host Microbe. 2012;11:617-30.

141. Kadowaki N, Ho S, Antonenko S, Malefyt RW, Kastelein RA, Bazan F, et al. Subsets of human dendritic cell precursors express different toll-like receptors and respond to different microbial antigens. J Exp Med. 2001;194:863-9.

142. Gotsman I, Grabie N, Gupta R, Dacosta R, MacConmara M, Lederer J, et al. Impaired regulatory T-cell response and enhanced atherosclerosis in the absence of inducible costimulatory molecule. Circulation. 2006;114:2047-55.

143. Conrad C, Gregorio J, Wang YH, Ito T, Meller S, Hanabuchi S, et al. Plasmacytoid dendritic cells promote immunosuppression in ovarian cancer via ICOS costimulation of Foxp3(+) T-regulatory cells. Cancer Res. 2012;72:5240-9.

144. Espinola-Klein C, Rupprecht HJ, Blankenberg S, Bickel C, Kopp $\mathrm{H}$, Victor A, et al. Impact of infectious burden on progression of carotid atherosclerosis. Stroke J Cereb Circ. 2002;33:2581-6.

145. Rupprecht HJ, Blankenberg S, Bickel C, Rippin G, Hafner G, Prellwitz W, et al. Impact of viral and bacterial infectious burden on long-term prognosis in patients with coronary artery disease. Circulation. 2001;104:25-31.

146. Hechter RC, Budoff M, Hodis HN, Rinaldo CR, Jenkins FJ, Jacobson LP, et al. Herpes simplex virus type 2 (HSV-2) as a coronary atherosclerosis risk factor in HIV-infected men: multicenter AIDS cohort study. Atherosclerosis. 2012;223:433-6.

147. Goossens P, Gijbels MJ, Zernecke A, Eijgelaar W, Vergouwe MN, van der Made I, et al. Myeloid type I interferon signaling promotes atherosclerosis by stimulating macrophage recruitment to lesions. Cell Metab. 2010;12:142-53.

148. Niessner A, Shin MS, Pryshchep O, Goronzy JJ, Chaikof EL, Weyand CM. Synergistic proinflammatory effects of the antiviral cytokine interferon-alpha and Toll-like receptor 4 ligands in the atherosclerotic plaque. Circulation. 2007;116:2043-52.

149. Ovchinnikova OA, Berge N, Kang C, Urien C, Ketelhuth DF, Pottier J, et al. Mycobacterium bovis BCG killed by extended freeze-drying induces an immunoregulatory profile and protects against atherosclerosis. J Intern Med. 2014;275:49-58.

150. Hansson GK, Nilsson J. Vaccination against atherosclerosis? Induction of atheroprotective immunity. Semin Immunopathol. 2009;31:95-101.

151. Zhou X, Caligiuri G, Hamsten A, Lefvert AK, Hansson GK. LDL immunization induces T-cell-dependent antibody formation and protection against atherosclerosis. Arterioscler Thromb Vasc Biol. 2001;21:108-14.

152. Yuan X, Yang X, Cai D, Mao D, Wu J, Zong L, et al. Intranasal immunization with chitosan/pCETP nanoparticles inhibits atherosclerosis in a rabbit model of atherosclerosis. Vaccine. 2008;26: 3727-34.

153. Garcia-Gonzalez V, Delgado-Coello B, Perez-Torres A, MasOliva J. Reality of a vaccine in the prevention and treatment of atherosclerosis. Arch Med Res. 2015;46:427-37.

154. Garcia-Gonzalez V, Gutierrez-Quintanar N, Mendoza-Espinosa P, Brocos P, Pineiro A, Mas-Oliva J. Key structural arrangements at the C-terminus domain of CETP suggest a potential mechanism for lipid-transfer activity. J Struct Biol. 2014;186:19-27.

155. Shimabukuro-Vornhagen A, Liebig T, von Bergwelt-Baildon M. Statins inhibit human APC function: implications for the treatment of GVHD. Blood. 2008;112:1544-5.
156. Yilmaz A, Reiss C, Weng A, Cicha I, Stumpf C, Steinkasserer A, et al. Differential effects of statins on relevant functions of human monocyte-derived dendritic cells. J Leukoc Biol. 2006;79:529-38.

157. Duivenvoorden R, Tang J, Cormode DP, Mieszawska AJ, Izquierdo-Garcia D, Ozcan C, et al. A statin-loaded reconstituted high-density lipoprotein nanoparticle inhibits atherosclerotic plaque inflammation. Nat Commun. 2014;5:3065.

158. Tang J, Lobatto ME, Hassing L, van der Staay S, van Rijs SM, Calcagno $\mathrm{C}$, et al. Inhibiting macrophage proliferation suppresses atherosclerotic plaque inflammation. Sci Adv. 2015;1.

159. Nahrendorf M, Keliher E, Marinelli B, Leuschner F, Robbins CS, Gerszten RE, et al. Detection of macrophages in aortic aneurysms by nanoparticle positron emission tomography-computed tomography. Arterioscler Thromb Vasc Biol. 2011;31:750-7.

160. Marrache S, Dhar S. Biodegradable synthetic high-density lipoprotein nanoparticles for atherosclerosis. Proc Natl Acad Sci U S A. 2013;110:9445-50.

161. Sanchez-Gaytan BL, Fay F, Lobatto ME, Tang J, Ouimet M, Kim Y, et al. HDL-mimetic PLGA nanoparticle to target atherosclerosis plaque macrophages. Bioconjug Chem. 2015;26:443-51.

162. Oh B, Lee CH. Development of Man-rGO for targeted eradication of macrophage ablation. Mol Pharm. 2015;12:3226-36.

163. Warnatsch A, Ioannou M, Wang Q, Papayannopoulos V. Inflammation. Neutrophil extracellular traps license macrophages for cytokine production in atherosclerosis. Science. 2015;349: 316-20.

164. Wang Z, Li J, Cho J, Malik AB. Prevention of vascular inflammation by nanoparticle targeting of adherent neutrophils. Nat Nanotechnol. 2014;9:204-10.

165. Park J, Gao W, Whiston R, Strom TB, Metcalfe S, Fahmy TM. Modulation of CD4+ T lymphocyte lineage outcomes with targeted, nanoparticle-mediated cytokine delivery. Mol Pharm. 2011;8:143-52.

166. Guillerey C, Mouries J, Polo G, Doyen N, Law HK, Chan S, et al. Pivotal role of plasmacytoid dendritic cells in inflammation and NK-cell responses after TLR9 triggering in mice. Blood. 2012;120:90-9.

167. Liu C, Lou Y, Lizee G, Qin H, Liu S, Rabinovich B, et al. Plasmacytoid dendritic cells induce NK cell-dependent, tumor antigen-specific $\mathrm{T}$ cell cross-priming and tumor regression in mice. J Clin Invest. 2008;118:1165-75.

168. Van Kaer L, Parekh VV, Wu L. Invariant natural killer T cells: bridging innate and adaptive immunity. Cell Tissue Res. 2011;343:43-55.

169. Tupin E, Kinjo Y, Kronenberg M. The unique role of natural killer $\mathrm{T}$ cells in the response to microorganisms. Nat Rev Microbiol. 2007;5:405-17.

170. Nagarajan NA, Kronenberg M. Invariant NKT cells amplify the innate immune response to lipopolysaccharide. J Immunol. 2007;178:2706-13.

171. Stubiger G, Wuczkowski M, Bicker W, Belgacem O. Nanoparticle-based detection of oxidized phospholipids by MALDI mass spectrometry: nano-MALDI approach. Anal Chem. 2014;86:6401-9.

172. Kharlamov AN, Tyurnina AE, Veselova VS, Kovtun OP, Shur VY, Gabinsky JL. Silica-gold nanoparticles for atheroprotective management of plaques: results of the NANOM-FIM trial. Nanoscale. 2015;7:8003-15.

173. Fredman G, Kamaly N, Spolitu S, Milton J, Ghorpade D, Chiasson $\mathrm{R}$, et al. Targeted nanoparticles containing the proresolving peptide Ac2-26 protect against advanced atherosclerosis in hypercholesterolemic mice. Sci Transl Med. 2015;7: $275 \mathrm{ra} 20$ 